\title{
EL ARGUMENTO DE ALVIN PLANTINGA CONTRA \\ EL NATURALISMO EVOLUCIONISTA: \\ UN ANÁLISIS CRÍTICO
}

\section{ALVIN PLANTINGA'S ARGUMENT AGAINST \\ EVOLUTIONARY NATURALISM: A CRITICAL REVIEW}

\author{
Antonio DiÉGUEZ* \\ Departamento de Filosofía \\ Universidad de Málaga
}

\begin{abstract}
Resumen: Alvin Plantinga ha desarrollado un atrevido argumento para probar que el naturalismo evolucionista no puede explicar por sí solo la posesión de capacidades cognitivas fiables. Según el argumento, si uno cree en la fiabilidad de nuestras capacidades cognitivas y en la teoría de la evolución, entonces debe abandonar el naturalismo y aceptar la intervención sobrenatural en la evolución de dichas capacidades, puesto que la probabilidad de que la evolución conduzca a la posesión de capacidades cognitivas fiables es baja o inescrutable. Con este argumento Plantinga utiliza una estrategia en defensa del diseño inteligente (de nuestras capacidades cognitivas) diferente de la usual: supone la validez del darwinismo para concluir que éste necesita del supernaturalismo si quiere explicar nuestro conocimiento. En el artículo se analiza críticamente este argumento.
\end{abstract}

PalabRas ClaVE: Naturalismo, teología, diseño providencial, darwinismo.

* e-mail: dieguez@uma.es 
ABSTRACT: Alvin Plantinga has proposed a daring argument to prove that the evolutionary naturalism is not able on its own to explain the existence of reliable cognitive abilities. According to the argument, if we accept the reliability of our cognitive abilities and the Darwinian theory of evolution, then we have to reject the naturalism and accept the supernatural intervention in the evolution of such abilities, since the probability that evolution had provided us with reliable cognitive abilities is low or inscrutable. In this way Plantinga uses a strategy in defence of intelligent design (of our cognitive abilities) which is different from the usual one: he assumes the validity of evolutionary theory and concludes that this theory has to be supplemented by supernaturalism in order to explain our knowledge. This paper offers a critical analysis of Plantinga's argument.

KEYWORDS: Naturalism, theology, providential design, Darwinism.

La epistemología evolucionista, como es bien sabido, es aquella rama de la epistemología naturalizada que, bajo el supuesto de que nuestras capacidades cognitivas son un producto de la evolución biológica, explora en qué medida los datos y las hipótesis de la biología evolucionista pueden ayudar en la dilucidación de los viejos (y los nuevos) problemas filosóficos acerca del conocimiento. Uno de esos viejos temas epistemológicos que han cobrado nuevo ímpetu cuando ha sido contemplado desde esta perspectiva ha sido el problema del realismo. ¿Son nuestras capacidades cognitivas, en tanto que adaptación a un medio físico y/o social, lo suficientemente fiables? ¿Podemos decir que, dado que han sido pulidas por la selección natural, nos proporcionan un conocimiento aproximadamente verdadero acerca del mundo? ¿O, por el contrario, la verdad es algo ajeno a la evolución, puesto que a la selección natural le basta que nuestra conducta nos lleve a un mayor éxito reproductivo, aunque dicha conducta esté basada en creencias falsas?

En otros lugares (cf. Diéguez 2002 y en preparación) he argumentado que los argumentos evolucionistas ayudan a perfilar el debate y proporcionan nuevos elementos de juicio, pero no son suficientes para dar la victoria a ninguno de los bandos en liza. Hay quizás motivos para decir que la alternativa realista presenta al menos una ventaja: puede explicar de forma simple y unificada por qué nuestras 
capacidades cognitivas tienen un valor adaptativo, a saber, porque tienden a producir creencias verdaderas y éstas a su vez tienden a generar conductas adaptativas ya que se corresponden a la situación real y a sus exigencias concretas. El antirrealista no puede hacer lo mismo porque no tiene a su disposición una conexión sistemática entre creencias falsas y conducta adaptativa. No obstante, debe admitirse que la estrategia argumentativa del realista es una inferencia de la mejor explicación y que, como tal, su fuerza en este caso es limitada.

Ahora bien, reconocer que la epistemología evolucionista no puede proporcionar argumentos definitivos en favor del realismo es una cosa, y otra muy distinta es creer que la evolución nos lleva a abrazar abiertamente el antirrealismo. Si el realismo no queda «demostrado» por la historia evolutiva de la cognición, no hay tampoco razones de peso para pensar, al modo de Nietzsche, que nuestras capacidades cognitivas, debido precisamente a su origen evolutivo, no pueden ser consideradas como fiables o incluso que sólo nos proporcionan ficciones reguladoras, ilusiones útiles para la supervivencia y la reproducción.

Uno de los autores que más claramente ha ensayado este camino —el de establecer que la evolución biológica no nos garantiza capacidades cognitivas fiables, sino más bien al contrario- y que ha intentado argumentarlo de forma más precisa es el filósofo norteamericano Alvin Plantinga. Plantinga, quien durante los últimos veinte años de su carrera docente fue profesor en la universidad católica de Notre Dame — aunque él es un fervoroso protestante-, ha sido un denodado defensor del teísmo desde una orientación analítica en filosofía. Sus obras sobre epistemología y filosofía de la religión tienen un amplio reconocimiento académico. Y precisamente, entre sus aportaciones más relevantes está el haber desarrollado un atrevido argumento para probar que, si uno cree en la fiabilidad de nuestras capacidades cognitivas y en la teoría de la evolución —como él mismo cree, aunque con muchos matices en lo que se refiere al origen del ser humano- ${ }^{1}$, entonces debe abandonar el naturalismo (entendido en el sentido ontológico fuerte de que sólo existen entidades naturales) y aceptar la intervención

${ }^{1}$ Hay lugares, sin embargo, en los que sus dudas sobre puntos centrales del evolucionismo le sitúan muy cerca de las tesis clásicas del creacionismo (cf., por ejemplo, Plantinga 1991), pero, al igual que los representantes más destacados del 'Diseño inteligente', Plantinga no niega el hecho de la evolución, ni que la teoría darwinista sea una explicación aceptable de ese hecho en muchos de sus aspectos. 
sobrenatural en la evolución de dichas capacidades. Sólo la intervención sobrenatural podría explicar que nuestras capacidades cognitivas alcancen un grado tan alto de fiabilidad como el que observamos, porque si tuviéramos que confiar sólo en la acción de la selección natural, la conclusión habría de ser, por el contrario, que nuestras capacidades cognitivas no deberían ser suficientemente fiables (cf. Plantinga 1993, cap. 12 y 2002a). El argumento, expuesto de forma detallada, es como sigue:

1. Si aceptamos el naturalismo $(\mathrm{N})$ y el evolucionismo (E), la probabilidad de que nuestras capacidades cognitivas sean fiables $(F)$, o sea $P(F / N \& E)$, es baja o inescrutable.

2. El naturalista evolucionista tiene entonces que aceptar un cancelador (defeater) de la creencia en la fiabilidad de nuestras capacidades cognitivas, es decir, tiene razones para rechazarla.

3. Si acepta que nuestras capacidades cognitivas no son fiables, entonces este cancelador no puede ser cancelado por ninguna otra creencia (ya que cualquiera otra creencia provendría de capacidades cognitivas no fiables).

4. El naturalista evolucionista tiene que aceptar que también su creencia en el naturalismo y el evolucionismo resulta cancelada.

5. Por tanto, la creencia en el naturalismo y el evolucionismo se cancela a sí misma.

Esto quiere decir que todo el que pretenda defender el evolucionismo, y especialmente el evolucionismo aplicado a nuestras capacidades cognitivas, debe rechazar el naturalismo.

Obviamente, la clave del argumento, al menos en el aspecto que aquí nos interesa, está en la primera premisa: en la afirmación de que la probabilidad de que nuestras capacidades cognitivas sean fiables, si asumimos el naturalismo y el evolucionismo, es baja o inescrutable. Sin embargo, antes de entrar en su análisis, hay que hacer una primera observación con respecto al argumento en general. Quizás la conclusión del argumento se pueda mantener si se establece que la probabilidad de que nuestras capacidades cognitivas sean fiables es baja dado el naturalismo y el evolucionismo, pero ¿por qué habríamos de mantenerla si dicha probabilidad fuera inescrutable? Podría ser que, siendo inescrutable para nosotros, fuera de hecho muy alta. ¿El que no podamos conocer esa alta probabilidad nos daría una razón para cancelar nuestra creencia en la fiabilidad de nuestras 
capacidades cognitivas? Desde luego esto es algo sumamente dudoso y Plantinga no realiza ninguna alegación convincente para que se acepte. Es más, incluso aunque la probabilidad sea baja, tampoco se sigue necesariamente la conclusión. Como han señalado algunos críticos, puede que la probabilidad sea baja sencillamente porque falta información relevante. En tal caso, no sería inconcebible que lleguemos a recabar datos adicionales, más allá de la teoría de la evolución y de la estricta tesis naturalista (aunque no contrarios a ellas), que aumenten la probabilidad de que tengamos capacidades cognitivas fiables (cf. Fitelson \& Sober 1998).

Pero dejemos de lado estas dudas acerca de la validez general del argumento. Admitamos que el argumento es válido y concentrémonos en el análisis de la primera premisa. ¿Qué razones aporta Plantinga para sostenerla? Fundamentalmente una: «El que hayamos evolucionado y sobrevivido únicamente haría probable que nuestras capacidades cognitivas fueran fiables y nuestras creencias verdaderas en su mayor parte si fuera imposible o improbable que criaturas similares a nosotros pudieran tener una conducta promotora de la adaptación (fitnessenhancing) manteniendo al mismo tiempo creencias en su mayor parte falsas.» (Plantinga 2002a, p. 5). Dicho en términos más directos, nuestras capacidades cognitivas podrían ser consideradas como fiables si pudiéramos establecer desde planteamientos evolucionistas que organismos como nosotros habrían sido incapaces de desplegar una conducta adaptativa sin que detrás de ella hubiera creencias verdaderas. Como Plantinga cree que no podemos establecer esto, entonces ha de aceptarse la premisa en cuestión.

¿Y por qué cree que no podemos establecer esto? La idea que está en la base es que la evolución no tiene por qué conducir a la posesión de capacidades cognitivas fiables si para la supervivencia y reproducción bastan capacidades cognitivas no fiables en su representación del mundo, pero efectivas en la consecución de esos fines. Para aclarar por qué es así Plantinga cree que debemos indagar acerca de la conexión entre creencias y conductas. El modo en que supongamos que nuestras creencias controlan nuestra conducta es fundamental para determinar en qué medida la selección natural ha podido actuar o no en favor de facultades que proporcionan creencias verdaderas en una proporción suficiente. Tal como él lo ve existen cuatro posibilidades al respecto:

a) Que nuestra conducta no esté causada por nuestras creencias (como sostiene el «epifenomenalismo»). En ese caso, y puesto que lo que importa 
desde el punto de vista de la selección natural es la conducta, las creencias serían invisibles para la evolución. Si esto es así, la probabilidad de que la evolución nos dotara con capacidades cognitivas fiables sería baja (o, en el mejor de los casos, inescrutable). No habría ninguna conexión relevante que pudiera llevar de la selección de determinada conducta a la selección de determinadas creencias.

b) Que nuestra conducta no esté causada por el contenido de nuestras creencias, sino por su sintaxis (posibilidad a la que llama «epifenomenalismo semántico»). En tal caso, de nuevo, la probabilidad de que la evolución nos dotara con capacidades cognitivas fiables sería baja o inescrutable, ya que la verdad es una propiedad semántica, no sintáctica, y sería invisible para la selección natural.

c) Que nuestra conducta esté causada por el contenido y la sintaxis de nuestras creencias, pero que dicha conducta sea inadaptativa (maladptive), es decir, que el organismo consiguiera una mayor eficacia biológica desprendiéndose de esas creencias. En tal caso, la probabilidad de que la evolución nos hubiera dotado con capacidades cognitivas fiables sería baja.

d) Que nuestra conducta esté causada por nuestras creencias y que éstas sean adaptativas. En tal caso, igualmente, la probabilidad de que la evolución nos hubiera dotado con capacidades cognitivas fiables sería también inescrutable (o, a lo sumo, moderadamente alta), puesto que «si la conducta está causada por la creencia, también está causada por el deseo (y otros factores — sospecha, duda, aprobación y desaprobación, miedo - que podemos ignorar aquí). Para cualquier acción adaptativa habría muchas combinaciones de estas creencias-deseos que podrían producir dicha acción; y muchas de estas combinaciones de creencias-deseos implicarían creencias falsas». (Plantinga 2002a, p. 8).

Podría parecer que la admisión por parte de Plantinga de que en el caso (d) la probabilidad de la fiabilidad de nuestras capacidades cognitivas pudiera ser moderadamente alta destruye el argumento, pues concede al realista, al menos en una de las alternativas posibles, lo que éste quiere. Pero él no lo ve así. La razón estriba en que, según su opinión, si se asume el naturalismo y el evolucionismo, las posibilidades (a) y (b) —y especialmente la (b) ${ }^{2}$ son mucho más probables que la

\footnotetext{
2 Plantinga acusa precisamente a Jerry Fodor, en la respuesta que éste da a su argumento, de ignorar esta posibilidad (b) (cf. Plantinga 2002b, pp. 211 y ss.).
} 
(c) y la (d); de modo que el resultado final — que contempla todas las posibilidades unidas - es que una probabilidad moderadamente alta de fiabilidad de nuestras capacidades cognitivas en el caso (d) queda menoscabada por la baja probabilidad de que precisamente el caso (d) sea aceptable desde el naturalismo evolucionista.

Por tanto, según la exposición de Plantinga, la posibilidad que lleva el peso del argumento es la (b). Sería la posibilidad más probable desde posiciones naturalistas (en todo caso así lo cree él) y conduce a atribuir una baja probabilidad a la posesión de capacidades cognitivas fiables. Y ello permitiría contrarrestar el que la posibilidad (d) — cuya probabilidad, por el contrario, es muy baja si aceptamos el naturalismo - conduzca a atribuir, con el realista, una probabilidad moderadamente alta a la posesión de tales capacidades cognitivas (cf. Plantinga 2002 b, p. 253) ${ }^{3}$. Desde el punto de vista del realismo, sin embargo, las posibilidades que verdaderamente importan para mostrar la debilidad del argumento son (c) y (d). Veamos cada una de ellas.

Para el naturalista, la posibilidad (a) no sólo no es muy probable, como cree Plantinga, sino que es prácticamente descartable. Debemos tener en cuenta que, aunque Plantinga hable directamente de creencias, aquello para lo que la mayor parte de los naturalistas pretenden encontrar una explicación evolucionista no son nuestras creencias aisladas, sino nuestras estructuras cognitivas en general. Ahora bien, la posibilidad (a) equivale a sostener una desconexión total entre

3 Este énfasis en la posibilidad (b) se percibe fundamentalmente en las réplicas de Plantinga a sus críticos. Simplificando, hay dos posibilidades: que nuestra conducta venga causada por el contenido de nuestras creencias (llamemos $\mathrm{C}$ a esta posibilidad) o que no venga causada por el contenido de nuestras creencias $(\neg \mathrm{C})$. Si aceptamos el naturalismo evolucionista, la probabilidad de C, según Plantinga, es muy baja, pongamos 0,2 y la de $(-C)$ es muy alta, pongamos 0,8 . Es decir, $\mathrm{P}(\mathrm{C} / \mathrm{N} \& \mathrm{E})=0,2$ y $\mathrm{P}(-\mathrm{C} / \mathrm{N} \& \mathrm{E})=0,8$. Por otra parte, la probabilidad de que nuestras capacidades cognitivas sean fiables si aceptamos el naturalismo evolucionista y consideramos que el contenido de nuestras creencias causa nuestra conducta es baja, pongamos 0,3 siendo generosos, esto es, $\mathrm{P}(\mathrm{F} / \mathrm{N} \& \mathrm{E} \&-\mathrm{C})=0,3$. En tal caso, aunque le concedamos la máxima probabilidad a la posesión de capacidades cognitivas fiables si el naturalismo evolucionista es correcto y nuestra conducta viene causada por el contenido de nuestras creencias, esto es, aunque asumamos que $\mathrm{P}(\mathrm{F} / \mathrm{N} \& \mathrm{E} \& \mathrm{C})$ $=1$, el resultado no alterará la primera premisa del argumento. En efecto, $\mathrm{P}(\mathrm{F} / \mathrm{N} \& \mathrm{E})=$ $\mathrm{P}(\mathrm{F} / \mathrm{N} \& \mathrm{E} \& \mathrm{C}) \times \mathrm{P}(\mathrm{C} / \mathrm{N} \& \mathrm{E})+\mathrm{P}(\mathrm{F} / \mathrm{N} \& \mathrm{E} \&-\mathrm{C}) \times \mathrm{P}(-\mathrm{C} / \mathrm{N} \& \mathrm{E})$. Sustituyendo en cada caso por los valores que hemos dado, tendremos que $\mathrm{P}(\mathrm{F} / \mathrm{N} \& \mathrm{E})=0,44$; o lo que es igual, la probabilidad de que tengamos capacidades cognitivas fiables si aceptamos el naturalismo evolucionista es baja pese a todo (cf. Plantinga 2002a, p. 10). 
nuestras capacidades cognitivas, o al menos sus funciones encargadas de la formación de creencias, y nuestra conducta. Esto no sólo resulta inaceptable desde un punto de vista evolucionista, sino que choca con todo lo que nos dice la psicología cognitiva.

En cuanto a (b), podría ser que, en efecto, algunos naturalistas se muestren inclinados a aceptarla, aunque es absolutamente cuestionable que ésta sea la posibilidad más probable si se acepta el naturalismo, tal como mantiene Plantinga. Si el epifenomenalismo semántico fuera correcto, esto es, si la semántica de nuestros procesos mentales estuviera tan desacoplada de su sintaxis — de sus aspectos físicos, podríamos decir- lo sorprendente desde un planteamiento evolucionista sería que poseyéramos estados mentales tan complejos y variados; y que no fuéramos simplemente zombis que actúan sin ninguna conciencia de lo que hacen ni de por qué lo hacen. El contenido de nuestros procesos mentales sería superfluo desde un punto de vista adaptativo, como lo es el sonido del corazón cuando cumple su función realmente adaptativa, que es bombear la sangre. Pero no parece plausible que el contenido de los procesos mentales sea un subproducto gratuito y no funcional de la actividad físico-química del cerebro; un subproducto dado por añadidura, pero carente de toda función, ya que nada cambiaría sin dicho contenido. El hecho, por ejemplo, de que muchas de nuestras decisiones se efectúen bajo deliberación consciente, tomando en cuenta por tanto el contenido de nuestras creencias y deseos, y no de forma automática, implica la posesión de un cerebro más complejo y más costoso desde el punto de vista metabólico de lo que habría sido en el caso contrario. Así pues, el naturalista cree que tiene buenas razones para suponer que los contenidos mentales cumplen un papel causal en nuestra conducta (cf. Searle 2001).

Ciertamente, la cuestión de la causación mental es controvertida y compleja, y en particular lo es el problema de la exclusión, que es el que aquí aparece implicado: si los estados o propiedades neurofisiológicos o físicos son la causa real de nuestra conducta, los estados mentales se vuelven entonces causalmente irrelevantes, so pena de atribuir dos causas suficientes a un mismo fenómeno. Exponer este problema con un mínimo de rigor nos llevaría a desviarnos demasiado de nuestro asunto ${ }^{4}$, pero nos basta con saber que el epifenomenismo semán-

\footnotetext{
${ }^{4}$ Para eximirme de esa tarea, remito al lector al muy completo libro de Josep Corbí y Josep Prades (2000).
} 
tico sería sólo una de las alternativas disponibles para el naturalista, y no precisamente la más frecuentada. Así, un fisicalista que identifique las propiedades mentales con las propiedades físicas subyacentes (identidad tipo/tipo, según la jerga al uso) podría esquivar el problema al modo en que Plantinga lo presenta. Las propiedades físicas serían las causantes de nuestra conducta, pero como éstas se identifican con las propiedades mentales, tanto da decir que es nuestra mente la causa de nuestra conducta (cf. Crane 1995). Tampoco cabe descartar sin más la posibilidad de una causación atribuible a los procesos mentales en tanto que procesos supervinientes con respecto a los procesos físicos. En esta línea habría que entender, por ejemplo, la propuesta de Jaegwon Kim (1993, cap. 6) cuando postula una 'causación epifenoménica'. En general, pocos naturalistas estarían dispuestos a aceptar esa separación tajante entre sintaxis y semántica que presupone esta posibilidad (b), y menos en este asunto. Por el contrario, es tan fuerte la evidencia empírica en favor de la influencia causal del contenido de nuestros procesos mentales sobre nuestra conducta que el epifenomenalismo semántico es más bien la posición a evitar para el naturalista, por mucho que haya que afinar las propuestas alternativas.

Pero además, dándole una vuelta más al asunto y aceptando por un momento que no hubiera una relación causal entre el contenido de nuestras creencias y nuestras acciones, esto no haría que dicho contenido fuera necesariamente invisible para la selección natural. Si tanto el contenido como la conducta obedecieran a una causa común, la selección podría actuar sobre el contenido de forma indirecta a través de esa causa común. Fitelson y Sober (1998) mencionan al respecto un ejemplo clásico en el evolucionismo: la resistencia a la malaria no causa anemia falciforme, ni la anemia falciforme causa resistencia a la malaria; y sin embargo, ambos rasgos están correlacionados en diversas poblaciones humanas debido a que son rasgos fenotípicos causados por el mismo gen.

¿Y qué decir de las posibilidades (c) y (d)? ¿Son tan plausibles como Plantinga cree?

Veamos (c). En mi opinión, del análisis de esta posibilidad parece seguirse más bien la conclusión contraria a la que Plantinga obtiene. Si nuestras creencias son las causantes de nuestra conducta pero el resultado es inadaptativo, entonces caben dos alternativas. La primera es que la inadaptación hubiera sido gra- 
ve, en cuyo caso no estaríamos aquí como especie y haría mucho que nos habríamos extinguido por dejarnos guiar en nuestra conducta de una forma en que disminuía sustancialmente nuestra adaptación al medio. La segunda es que la inadaptación no hubiera sido muy grave. Pero esta alternativa no mejora mucho las cosas para Plantinga, pues entonces es de suponer que la selección natural habría eliminado pronto unas capacidades cognitivas sumamente costosas desde un punto de vista fisiológico y que conducen a conductas levemente perjudiciales para la eficacia biológica del organismo. Dado que ni nos hemos extinguido ni, al menos en un número significativo de casos, nos hemos visto desprovistos de nuestras capacidades cognitivas, la conclusión a sacar es que la posibilidad (c) ha de ser descartada. Nuestras capacidades cognitivas no pueden ser la causa de conductas inadaptativas generalizadas.

Una forma posible de escapar a esta objeción sería sostener que nuestras capacidades cognitivas conducen a conductas inadaptativas pero que, pese a todo, se mantienen evolutivamente debido a efectos pleiotrópicos. Es decir, vendrían codificadas por genes que codifican al mismo tiempo otros rasgos que sí son adaptativos y que, al ser potenciados por la selección natural, mantendrían como efecto indirecto la existencia de esas capacidades cognitivas inadaptativas. De este modo, por utilizar la famosa distinción de Elliott Sober, habría habido una selección de nuestras capacidades cognitivas, pero no por ser capacidades cognitivas. Este escenario, sin embargo, es a priori sumamente improbable. Por un lado, no se conocen efectos pleiotrópicos de este tipo en relación a las capacidades cognitivas. Pero no es eso lo más importante — todavía conocemos muy poco del funcionamiento coordinado y de las relaciones estructurales de nuestros genes. Lo que hace improbable esta posibilidad es otra cosa. Si nuestras capacidades cognitivas vinieran posibilitadas por un solo gen o por un pequeño número de ellos, todavía podría admitirse lo que la posibilidad (c) contempla, aún cuando el incremento en eficacia biológica proporcionado por esos otros rasgos tendría que haber sido muy grande para poder compensar el enorme coste energético de nuestro cerebro; pero si consideramos que el número de genes implicados ha de ser muy grande, como parece que es el caso, sería una extraña coincidencia que todos ellos (o una gran mayoría) estuvieran implicados en efectos pleiotrópicos que dotaran al organismo de rasgos altamente adaptativos que compensaran la conducta inadaptativa. Por las mismas razones habría que descartar que la posibilidad (c) se efectuara debido a la existencia de ligaduras genéticas. 
Sólo nos queda entonces por revisar la posibilidad (d), de acuerdo con la cual la posesión de capacidades cognitivas fiables es inescrutable o moderadamente alta. Ya hemos dicho - y esto es algo que no terminan de ver algunos de sus críticos y no pocos de sus defensores- que para Plantinga esta posibilidad no es decisiva, porque la estima como muy improbable dado el naturalismo evolucionista. Pero merece la pena detenerse en su desarrollo y en la razón que Plantinga aduce para considerar inescrutable la probabilidad de tener capacidades cognitivas fiables por mecanismos puramente evolutivos porque sacaremos alguna enseñanza interesante de ello.

Según Plantinga, las mismas conductas adaptativas que desplegamos en nuestro trato con el entorno, y que el realista considera como tales por proceder de creencias verdaderas, podrían haber sido producidas por una serie de conjunciones alternativas de creencias y deseos en las que las creencias de base serían falsas. Por ejemplo, podríamos haber huido ante la visión de un tigre por haber tenido el deseo de acariciarlo unido a la creencia de que el mejor modo de conseguirlo es huir de él, o por haber tenido la creencia de que la aparición de un tigre era la señal de salida en una carrera atlética unida al deseo de participar en la carrera. Estas combinaciones habrían sido tan adaptativas como huir del tigre por tener la creencia de que nos podía devorar y el deseo de no ser devorado. Al fin y al cabo, su efecto en nuestra conducta sería el mismo, así como el resultado adaptativo final: el tigre no nos habría devorado.

Hay que conceder que ésta es una posibilidad no descartable lógicamente, pero el realista está en su derecho de exigir una explicación acerca de cómo unas facultades cognitivas que proporcionaran sistemáticamente creencias tan singulares habrían evolucionado de hecho5. ¿Habría habido quizás una presión selectiva orientada a la posesión de órganos sensoriales generadores de ilusiones pero bien coordinados entonces con nuestros sistemas productores de conducta para poder dar con un resultado que, pese a la ilusión sensorial, permitiera un incremento en las posibilidades de supervivencia y reproducción del organismo? ¿ $\mathrm{O}$

5 Es importante subrayar lo de «sistemáticamente», porque de otro modo sería discutible si hay razones para considerar como no fiables a nuestras capacidades cognitivas. Por dejarlo claro, unas capacidades cognitivas capaces de generar un $80 \%$ de creencias verdaderas serían, para el que esto escribe al menos, bastante fiables, especialmente si el $20 \%$ de los errores se concentran en asuntos alejados de la vida cotidiana. 
estaría más bien la fuente de falsedades en nuestras prácticas inferenciales, o en nuestra memoria, en cuyo caso son éstas las que deberían haber evolucionado de forma que los errores condujeran de forma generalizada a conductas exitosas?

En una situación semejante habría que explicar cómo es posible que esas falsas creencias, en combinación con otras creencias y otros deseos, sigan generando una conducta adaptativa en situaciones contextualmente muy diferentes, como se supone que hacen las creencias verdaderas. Plantinga podría argüir que para cualquier combinación de creencias verdaderas y deseos que conduzca a una conducta adaptativa puede siempre encontrarse otra combinación con resultados iguales pero basada en creencias falsas. Pero aún admitiendo que esto sea así, esta combinación habría de ser establecida de una forma ad hoc y no tendría por qué mantener su eficacia frente a los cambios de contexto. Una recombinación de creencias verdaderas y adaptativas sobre nuestro entorno seguiría muy posiblemente siendo adaptativa (desde luego para el realista lo sería, ya que la combinación seguiría siendo verdadera y, por tanto, está en condiciones de generar en caso de necesidad una conducta adaptativa), mientras que no hay razón para esperar lo mismo de una recombinación de creencias falsas ${ }^{6}$.

Si aceptamos que la evolución no selecciona creencias individuales, sino, en todo caso, mecanismos para generarlas, el realista tiene una explicación de por qué tenemos esos mecanismos: las creencias verdaderas son todas ellas, por el hecho de ser adecuadas a la realidad, potencialmente capaces de dar lugar a conductas adaptativas, mientras que difícilmente las creencias falsas pueden tener un éxito duradero, y por ello la evolución ha ido en la dirección de seleccionar mecanismos cognitivos fiables. Unos mecanismos cognitivos no fiables no habrían podido ser mantenidos por la selección natural. Ya hemos dicho que esa explicación no tiene toda la fuerza que el realista querría, pero en todo caso es una explicación coherente y defendible. En cambio, el antirrealista no tiene a su dis-

${ }^{6}$ A no ser que el mecanismo para generar creencias falsas sea completamente parasitario del mecanismo para generar creencias verdaderas. Un mecanismo así es el que tiene en mente Plantinga cuando, para escapar de esta crítica, dice que bastaría con considerar a un individuo que creyera en todo lo que cree otro individuo con creencias verdaderas pero en cada una de ellas añadiera que todo ha sido creado por Dios. Según Plantinga, el naturalista estaría entonces en una situación en la que todas sus creencias son falsas pero su valor adaptativo sería el mismo que las del otro individuo (cf. Plantinga 2002b, p. 265). Sin embargo, ¿proporciona esta salida una victoria reseñable sobre el realista? 
posición en este punto una explicación comparable, a no ser que confíe en que una creencia falsa, por el mero hecho de serlo, puede generar conductas adaptativas. En otros términos, el antirrealista no tiene una explicación convincente de cómo nuestras capacidades cognitivas podrían dar lugar a creencias falsas que sistemáticamente, y no sólo aisladamente, conduzcan a conductas adaptativas. Por no mencionar el hecho de que, incluso en las combinaciones de creencias falsas, como las que Plantinga menciona en sus ejemplos, debe seguir habiendo una gran cantidad de creencias verdaderas acompañantes para que el conjunto tenga algún sentido y para que el resultado sea una acción exitosa; como, por ejemplo, que el tigre es real, que es un ente material, que no es un puercoespín y, por tanto, puedo acariciarlo, que está a una cierta distancia de mí, que el tigre y yo somos cosas distintas, etc. Sencillamente un error radical, un error masivo del tipo 'genio maligno' o del tipo 'cerebro en una cubeta', aunque lógicamente posible, es evolutivamente inviable.

En su réplica al argumento de Plantinga, Jerry Fodor se centra precisamente en esta reclamación ${ }^{7}$ :

[...] ¿[C]ómo se las arregló en nuestro caso la evolución para conseguir lo que se necesitaba? El darwinismo, recordémoslo, es una tesis histórica acerca de nosotros. [...] Que, en principio, haya sistemas de creencias falsas generalmente exitosas no es suficiente para mostrar [que nuestras mentes evolucionaron bajo una selección que nos favoreció porque nuestras creencias falsas eran generalmente exitosas]; ni es suficiente que pudieran existir criaturas muy parecidas a nosotros cuyas mentes evolucionaran bajo la selección para tener creencias falsas y cuya conducta fuera generalmente exitosa. Lo que hace falta [...] es un escenario históricamente plausible de acuerdo con el cual nuestras mentes fueron seleccionadas debido a que teníamos montones de creencias falsas exitosas. (Fodor 2002, p. 37).

Evidentemente, Fodor cree que tal escenario no existe. Y no existe porque resulta por completo implausible. «Lo que todos creemos — continúa- es que cuando las acciones salidas de las creencias falsas son exitosas, eso es generalmente un accidente afortunado; $y$, en correspondencia, que una política de actuación

\footnotetext{
7 En el mismo sentido se expresan William Ramsey (2002) y Evan Fales (2002).
} 
basada en falsas creencias, incluso aunque funcione a corto plazo, generalmente le pone a uno en dificultades tarde o temprano». (p. 38). Por su parte, Ramsey escribe:

En lugar de proporcionarnos pares específicos de creencias-deseos que produzcan una conducta preservadora de la vida en ciertas circunstancias extrañas, Plantinga ha de describir los mecanismos o procesos generales que resultarían ser adaptativos mientras que generan preponderantemente creencias falsas. En otras palabras, lo que Plantinga tiene que explicar para poder desafiar la fiabilismo evolucionista es un mecanismo o proceso que (a) pueda desarrollarse a través de la evolución, (b) genere a través del tiempo mayormente creencias falsas, y (c) resulte, no obstante, ser adaptativo. (Ramsey 2002, p. 20).

En su réplica a Fodor, Plantinga traslada el peso de la prueba a sus críticos. Es el naturalista el que tendría que mostrar cómo puede ser que el contenido de nuestras creencias pueda actuar como causa de nuestra conducta y pueda ser seleccionado por ser verdadero. La forma en que un naturalista (materialista) suele hacerlo es, según Plantinga, considerando que el contenido de nuestras creencias es «idéntico a o superviene a partir de propiedades neurológicas u otras propiedades físicas» (Plantinga 2002b, pp. 216). Ahora bien, entonces estamos de nuevo ante la posibilidad (b). La selección natural estaría actuando sobre esas propiedades neurológicas o físicas, y no directamente sobre el contenido de nuestras creencias. Esto quiere decir que el hecho de que ese contenido sea verdadero o falso es irrelevante desde el punto de vista evolutivo:

[La selección natural] modifica las estructuras productoras-de-conductas en la dirección de una mayor adaptatividad, de un aumento de la eficacia biológica; al hacerlo, presumiblemente modifica el contenido, puesto que diferentes combinaciones de propiedades neurofisiológicas pueden implicar contenidos diferentes; pero no hay la más mínima razón para pensar que modificando las estructuras productoras-de-conductas en la dirección de la adaptatividad modificará también el contenido en la dirección de la verdad. [...] Sería un milagro cósmico (o quizás magia cósmica, o una enorme coincidencia cósmica) si la adaptatividad con respecto a las propiedades neuropsicológicas estuvieran correlacionadas con la verdad del contenido asociado. (p. 219). 
Ya hemos visto, sin embargo, que ni el epifenomenalismo ni la identificación de los contenidos mentales con propiedades neurológicas, o su reducción a las mismas, son las únicas salidas posibles para el naturalista (cf. Robb 2003, Yoo 2006). Por discutibles y problemáticas que sean, caben otras alternativas naturalistas acerca del problema de la causación mental. Por otra parte, el realista puede replicar que el milagro cósmico sería más bien el contrario al que Plantinga señala. El milagro sería que la adaptatividad de (la conducta generada por) las propiedades neuropsicológicas no estuviera de ningún modo relacionada con la verdad de su contenido. ¿Cómo explicar entonces su adaptatividad?

Pero sobre todo, esta réplica, en buena medida, desvía la cuestión del asunto verdaderamente relevante. Una cosa es que el realista no tenga una teoría adecuada de la causación mental (nadie la tiene) y otra es que Plantinga haya mostrado que la posibilidad (d) ha de ser asumida por las razones que él da. Es verdad que el realista no puede ofrecer una explicación completamente naturalista de las cuestiones semánticas fundamentales $\mathrm{y}$, desde luego no posee una respuesta definitiva acerca de cómo se relaciona una creencia verdadera con ciertas propiedades neurológicas o físicas y, por tanto, de cómo puede ser causalmente relevante con respecto a cierta conducta. Aún así, esto no prueba que Plantinga tenga razón al afirmar que la verdad es irrelevante en este asunto. No basta con decir, como él hace, que la probabilidad de que nuestras capacidades cognitivas sean fiables si admitimos el naturalismo, el evolucionismo y la causación de nuestra conducta por nuestras creencias es baja porque no sabemos cómo podría producirse dicha causación (cf. Plantinga 2002b, p. 220). Del hecho de que no dispongamos de una semántica naturalizada satisfactoria ni hayamos resuelto los problemas de la metafísica de la mente no podemos concluir que la evolución de nuestras capacidades cognitivas ha estado por completo desligada del contenido de las creencias que ellas mismas producían. Más bien hay motivos suficientes para pensar lo contrario: puesto que creemos que la función y el destino evolutivo de nuestras capacidades cognitivas no está desligado de su papel causal en nuestra conducta, pensamos que nuestras creencias deben, de un modo u otro, ser causa de nuestra conducta.

Fodor, en su crítica al argumento de Plantinga, llega a la misma conclusión que estamos tratando de apoyar aquí: que el darwinismo no permite establecer de forma definitiva que la mayor parte de lo que creemos es verdadero, ni tampoco lo contrario. Desde el análisis de las propuestas efectuadas tanto desde el 
lado realista como desde el lado antirrealista ésta es, al menos por el momento, la posición más adecuada ${ }^{8}$. Siendo más explícito: el realista no ha conseguido mostrar que poseemos capacidades cognitivas fiables porque éstas son una adaptación al medio', ni el antirrealista puede explicar satisfactoriamente cómo capacidades cognitivas no fiables pueden incrementar de forma sistemática la eficacia biológica de un organismo cuya evolución le ha dotado de capacidades cognitivas.

\section{Bibliografía}

Corbí, J. E. y J. L. Prades 2000: Minds, Causes, and Mechanisms, Oxford: Blackwell.

Crane, T. 1995: «The Mental Causation Debate», Proceedings of the Aristotelian Society, Supplementary Volume 69: 211-236.

DiÉGUEZ, A. 2002: «Realismo y epistemología evolucionista de los mecanismos cognitivos», Critica, vol. 34, no 102: 3-28.

- (En preparación) La evolución del conocimiento. De la mente animal a la mente humana..

FALES, E. 2002: "Darwin's Doubt, Calvin's Calvary», en J. Beilby (ed.), Naturalism Defeated? Essays on Plantinga's Evolutionary Argument against Naturalism, Ithaca: Cornell University Press: 43-58.

Fitelson, B. y Sober, E. 1998: «Plantinga’s Probability Argument against Evolutionary Naturalism», Pacific Philosophical Quarterly, 79: 115-129. Disponible online URL = http://fitelson.org/plant.pdf.

FODOR, J. 2002: «Is Science Biologically Possible?», en J. Beilby (ed.), Naturalism Defeated? Essays on Plantinga's Evolutionary Argument against Naturalism, Ithaca: Cornell University Press: 30-42.

Kitcher, Ph. 1992: «The Naturalism Return», Philosophical Review, 101: 53-114.

8 De forma parecida se manifiesta también Philip Kitcher (1992, p. 92): «Nadie que haya degustado los sutiles y rigurosos análisis de los mejores estudios evolucionistas tendrá mucha paciencia con descripciones causales que parecen tener más parentesco con Kipling que con Darwin. La respuesta correcta no es ni optimismo ni pesimismo, sino agnosticismo".

9 No debe olvidarse que mostrar que algún rasgo es adaptativo es una tarea difícil y engorrosa en la biología evolucionista que debe hacerse con rigor empírico si no se quiere caer en el vicio del "panglossianismo» que denunciaron Gould y Lewontin. 
KIM, J. 1993: Supervenience and Mind, Cambridge: Cambridge University Press.

Plantinga, A. 1991: «When Faith and Reason Clash: Evolution and the Bible», Christian Scholar Review, 21: 8-32. Reimpreso en D. L. Hull \& M. Ruse (eds.), The Philosophy of Biology, Oxford: Oxford University Press, 1998: 674-697.

- 1993: Warrant and Proper Function, New York: Oxford University Press.

- 1994: «Naturalism Defeated», artículo inédito. Disponible online URL = http://www.homestead.com/philofreligion/files/alspaper.htm

- 2002a: «Introduction. The Evolutionary Argument against Naturalism: An Initial Statement of the Argument», en J. Beilby (ed.), Naturalism Defeated? Essays on Plantinga's Evolutionary Argument against Naturalism, Ithaca: Cornell University Press: $1-12$.

— 2002b: «Reply to Beilby's Cohorts», en J. Beilby (ed.), Naturalism Defeated? Essays on Plantinga's Evolutionary Argument against Naturalism, Ithaca: Cornell University Press: 204-275.

RAmSeY, W. 2002: «Naturalism Defended», en J. Beilby (ed.), Naturalism Defeated?, Ithaca: Cornell University Press: 15-29.

Roвb, D. 2003: «Mental Causation», en Stanford Encyclopaedia of Philosophy, E. N. Zalta (ed.), URL = http://plato.stanford.edu/entries/mental-causation/

Searle, J. 2001: «Free Will as a Problem in Neurobiology», Philosophy, 76: 491-514.

Yoo, J. 2006: «Mental Causation», The Internet Encyclopedia of Philosophy, J. Fieser y B. Dowden (eds.), URL = http://www.iep.utm.edu/m/mental-c.htm

Recibido: 30/07/2009

Revisado: 15/08/2009 